\title{
Glycoprotein NMB: a novel Alzheimer's disease associated marker expressed in a subset of activated microglia
}

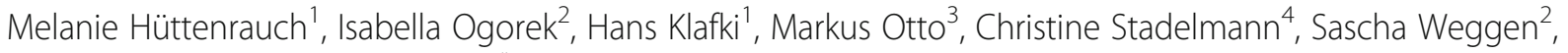
Jens Wiltfang ${ }^{1,5}$ and Oliver Wirths ${ }^{1 *}$

\begin{abstract}
Alzheimer's disease (AD) is an irreversible, devastating neurodegenerative brain disorder characterized by the loss of neurons and subsequent cognitive decline. Despite considerable progress in the understanding of the pathophysiology of $\mathrm{AD}$, the precise molecular mechanisms that cause the disease remain elusive. By now, there is ample evidence that activated microglia have a critical role in the initiation and progression of AD. The present study describes the identification of Glycoprotein nonmetastatic melanoma protein B (GPNMB) as a novel ADrelated factor in both transgenic mice and sporadic AD patients by expression profiling, immunohistochemistry and ELISA measurements. We show that GPNMB levels increase in an age-dependent manner in transgenic AD models showing profound cerebral neuron loss and demonstrate that GPNMB co-localizes with a distinct population of IBA1-positive microglia cells that cluster around amyloid plaques. Our data further indicate that GPNMB is part of a microglia activation state that is only present under neurodegenerative conditions and that is characterized by the up-regulation of a subset of genes including TREM2, APOE and CST7. In agreement, we provide in vitro evidence that soluble A $\beta$ has a direct effect on GPNMB expression in an immortalized microglia cell line. Importantly, we show for the first time that GPNMB is elevated in brain samples and cerebrospinal fluid (CSF) of sporadic AD patients when compared to non-demented controls.

The current findings indicate that GPNMB represents a novel disease-associated marker that appears to play a role in the neuroinflammatory response of $\mathrm{AD}$.
\end{abstract}

Keywords: Alzheimer's disease (AD), Glycoprotein nonmetastatic melanoma protein B (GPNMB), Neuroinflammation, Activated microglia, Sporadic AD patients, Transgenic mice, 5XFAD

\section{Introduction}

Alzheimer's disease (AD) is a progressive, age-associated neurodegenerative disorder and the most frequent cause of dementia among the elderly population. Major neuropathological hallmarks of $\mathrm{AD}$ include an abnormal accumulation of extracellular $\beta$-amyloid $(A \beta)$ peptides and intraneuronal neurofibrillary tangles composed of hyperphosphorylated tau protein. The disease involves extensive loss of synapses and neuronal death in the cerebral cortex and hippocampus, leading to gradual memory

\footnotetext{
* Correspondence: owirths@gwdg.de

'Department of Psychiatry and Psychotherapy, University Medical Center

(UMG), Georg-August-University, Von-Siebold-Str. 5, 37075 Göttingen,

Germany

Full list of author information is available at the end of the article
}

loss and cognitive decline. Despite considerable efforts during the last decades to find an efficacious therapy to halt or reverse AD pathology, currently available drugs allow at best an alleviation of the symptoms but do not affect the underlying cause of the disease [44].

Apart from amyloid plaques and intracellular tau aggregates, neuroinflammation represents an additional hallmark of AD. An increase in neuroinflammatory markers such as nitric oxide, interleukin-1 $\beta$ (IL-1 $\beta$ ) and tumor necrosis factor (TNF- $\alpha$ ) has been widely reported in brains of both Alzheimer's disease patients and transgenic AD models (reviewed in [14]). Emerging evidence suggests that instead of solely being a passive response to aberrant protein aggregation in the brain, persistent neuroinflammation might play a causal role in the 
pathogenesis of $\mathrm{AD}$. This hypothesis is supported by recent genome-wide association studies (GWAS) linking specific polymorphisms in inflammation-associated genes such as complement receptor-1 (CR1) [26], CD33 [13, 31] or triggering receptor expressed on myeloid cells-2 (TREM2) [8] to an increased risk for AD. Therefore, a detailed understanding of immunological processes associated with the disease has become a major goal in Alzheimer's research in order to evaluate modulation of neuroinflammation as a new therapeutic modality.

In a previous project, we performed a whole-brain transcriptome study to identify genes differentially expressed in the brains of 6-month-old APP/PS1KI mice compared to age-matched PS1KI and WT controls [51]. APP/PS1KI mice are a widely used $\mathrm{AD}$ model showing profound neuron loss in several brain regions, as well as working memory deficits and disturbed long-term potentiation $[3,5,55]$. The majority of genes that we discovered to be upregulated in APP/PS1KI mice compared to both control groups were implicated in inflammation-associated pathways and included intensively studied genes such as TREM2. Intriguingly, one of the most strongly up-regulated genes in the APP/PS1KI model was Glycoprotein nonmetastatic melanoma protein B (GPNMB), a gene that so far has not been implicated in $\mathrm{AD}$ [51].

GPNMB (also known as osteoactivin, OA) is a type I transmembrane glycoprotein that was initially described in a poorly metastatic melanoma cell line [52]. GPNMB is at least partially localized to the cell surface and ectodomain shedding by ADAM10 can release its large $\mathrm{N}$-domain into the extracellular space [40]. Since its identification, GPNMB expression has been detected in multiple tissues such as bone, kidney and skeletal muscle where it is implicated in various cellular processes like cell differentiation, tumor progression and tissue regeneration $[1,25,34,53]$. Furthermore, there is profound evidence that GPNMB has a function as a negative regulator of inflammatory processes. In macrophages, overexpression of GPNMB reduced the secretion of proinflammatory cytokines in vitro [39]. More recent data (in peripheral tissues) further indicate that GPNMB promotes the polarization of macrophages into an anti-inflammatory "M2" status, which results in the secretion of anti-inflammatory cytokines such as IL-10 and TGF- $\beta[59,61]$. Interestingly, in the central nervous system, GPNMB expression was identified within motor neurons, radial glia and most abundantly in microglia cells, which are the resident immune cells of the brain. Therefore, it has been proposed that GPNMB might also play a role in inflammatory processes in the CNS [15]. Furthermore, GPNMB has been shown to be elevated in brain and/or plasma of numerous neurodegenerative diseases such as Gaucher disease [23, 62], Niemann-Pick Type C disease [28] and amyotrophic lateral sclerosis (ALS) [48]. However, the impact of GPNMB overexpression on the pathophysiology of these diseases has not been elucidated.
The aim of the present work was to investigate a potential role of GPNMB in transgenic AD mouse models and human patients with sporadic AD. We demonstrate an age-dependent increase in GPNMB mRNA and protein levels in different $\mathrm{AD}$ mouse models. In addition, we discovered that GPNMB expression increases in parallel with $A \beta$ plaque deposition, therefore reflecting disease severity. Moreover, increased GPNMB levels were observed in the cerebrospinal fluid (CSF) and brains of human patients with sporadic AD.

\section{Material and methods \\ Transgenic mice}

The generation of 5XFAD mice (Tg6799) has been described previously [33]. In brief, 5XFAD mice overexpress APP695 carrying the Swedish, Florida and London mutations under the control of the murine Thy-1 promoter. Additionally, human presenilin-1 (PSEN1), carrying the familial Alzheimer's disease (FAD)-linked mutations M146 L and $\mathrm{L} 286 \mathrm{~V}$, is also expressed under the control of the murine Thy-1 promoter. 5XFAD mice used in this study were backcrossed for more than 10 generations to $\mathrm{C} 57 \mathrm{Bl} / 6 \mathrm{~J}$ wild-type mice (WT) from the Jackson Laboratory (Jackson Laboratories, Bar Harbor, ME, USA) to obtain an incipient congenic line on a C57BL/6 J genetic background.

The generation of APP/PS1KI mice has also been described [5]. APP/PS1KI mice express human mutant APP751 carrying the Swedish and London mutations under the control of the murine Thy-1 promoter. In addition, murine PSEN1 containing the M233 T and L235P mutations is expressed under the control of the endogenous mouse PSEN1 promoter. The APP/PS1KI mouse model was a generous gift of Dr. Laurent Pradier, Sanofi-Aventis, Paris, France.

The APP23 model was originally described by Sturchler-Pierrat and colleagues [46]. In this AD mouse model, human APP751 with the Swedish double-point mutation $\mathrm{K} 670 \mathrm{M} / \mathrm{N} 671 \mathrm{~L}$ is overexpressed under the control of the murine Thy-1 promoter. APP23 mice were a generous gift of Dr. Mathias Staufenbiel, Novartis, Basel, Switzerland. All animals were handled according to German guidelines for animal care.

\section{Patient samples \\ Human brain samples}

Human frozen brain samples from sporadic $\mathrm{AD}(n=9$, mean age $79.78 \pm 11.28$ years, Braak stage $\mathrm{V}-\mathrm{VI})$ and non-demented control subjects (NDC, $n=9$, mean age 82 \pm 9.77 years, Braak stage I-II), as well as paraffin-embedded $\mathrm{AD}$ and NDC samples for immunohistochemistry were obtained from the Netherlands Brain Bank. The present study was approved by the ethics committee of the University Medical Center Göttingen (12/1/15). Details regarding autopsy procedure can be found at www.brainbank.nl. 
Characteristics of the study cohort are presented in Additional file 1.

\section{Human CSF samples}

Human cerebrospinal fluid (CSF) and corresponding serum samples from patients suffering from sporadic $\mathrm{AD}(n=10$, mean age 70.4 \pm 7.56 years) and NDC subjects $(n=10$, mean age $62.5 \pm 9.32)$ were obtained by lumbar puncture, centrifuged, aliquoted and stored within $2 \mathrm{~h}$ at $-80{ }^{\circ} \mathrm{C}$ until analysis. All patients were seen at the Department of Neurology in Ulm (Ethical approval number 20/10). Characteristics of the study cohort are presented in Additional file 1.

\section{Cell culture and treatment conditions}

Murine immortalized microglial BV-2 cells were grown in DMEM/F-12 media supplemented with $10 \%$ heat-inactivated fetal bovine serum (FBS, Biochrom), $2 \mathrm{mM}$ L-Alanyl-L-Glutamine (Sigma-Aldrich) and non-essential amino acids (Sigma-Aldrich). SH-SY5Y cells stably overexpressing APP695 containing the Swedish mutation K670 N/M671 L and carrying a Myc tag and a carboxy-terminal Flag tag [29] were cultured in DMEM/ F-12 media supplemented with $10 \%$ heat-inactivated FBS, $2 \mathrm{mM}$ L-Alanyl-L-Glutamine, non-essential amino acids, and $50 \mu \mathrm{g} / \mathrm{ml}$ Hygromycin B (Carl Roth). Cells were maintained at $37^{\circ} \mathrm{C}$ in a humidified atmosphere containing $5 \%$ $\mathrm{CO}_{2}$. BV-2 cells were seeded into $9.6 \mathrm{~cm}^{2}$ petri dishes $\left(3 \times 10^{5}\right.$ cells/dish; $n=6 /$ treatment group), cultured for $24 \mathrm{~h}$, and then stimulated with lipopolysaccharide (LPS) $(0.1 \mu \mathrm{g} / \mathrm{ml})$, conditioned media of SH-SY5Y cells, or $\mathrm{A} \beta_{1-}$ ${ }_{42}(5 \mu \mathrm{M})$ for $24 \mathrm{~h}$ at $37^{\circ} \mathrm{C}$ with $5 \% \mathrm{CO}_{2}$. Then cells were collected for RNA extraction. $\mathrm{A} \beta_{1-42}$ peptides were purchased from Peptide Speciality Laboratory (PSL) and resuspended in $20 \mathrm{mM} \mathrm{NaOH}$ (final concentration, $1 \mathrm{mg} /$ $\mathrm{ml}$ ) directly before treatment of BV-2 cells. To obtain $\mathrm{A} \beta$-containing conditioned SH-SY5Y media, cells were plated in a $175 \mathrm{~cm}^{2}$ cell culture flask w/o Hygromycin B and incubated for $48 \mathrm{~h}$. The conditioned media were collected, centrifuged for $5 \mathrm{~min}$ at $1400 \mathrm{rpm}$, and applied to BV-2 cells for the indicated period of time.

Immunohistochemistry and immunofluorescence analyses Mice were killed by $\mathrm{CO}_{2}$ anesthetization followed by cervical dislocation. Brains and spinal cords were carefully dissected and post fixation for at least one week was carried out in $4 \%$ phosphate-buffered formalin at $4{ }^{\circ} \mathrm{C}$ before the tissue was embedded in paraffin. Immunohistochemistry was performed on $4 \mu \mathrm{m}$ paraffin sections as described previously [38]. The following antibodies were used: anti-A $\beta$ antibody 24311 (1:500, [41]), IBA1 (1:500; \#234004, Synaptic Systems) and GPNMB (1:500, Santa Cruz). Biotinylated secondary anti-rabbit, anti-guinea pig and anti-goat antibodies (1:200) were purchased from
Dako or Jackson Immunoresearch. The staining was visualized using the avidin-biotin complex method with a VECTASTAIN kit (Vector Laboratories) and diaminobenzidine (DAB) as a chromogen providing a reddish-brown color with hematoxylin as nuclear counterstain.

For double-immunofluorescence staining, polyclonal goat anti-GPNMB antibody (1:500, AF2330, R\&D Systems) was combined with IC16 (1:1000, against the N-terminus of A $\beta)$, GFAP (1:500, \#173004, Synaptic Systems), NeuN (1:300, MAB377, Millipore) and IBA1 (1:500, \#234004, Synaptic Systems), respectively. The staining was visualized using Alexa Fluor 594- and Alexa Fluor 488-conjugated secondary antibodies (1:750, Jackson Immunoresearch) and analyzed using a Nikon Eclipse Ti-E fluorescent microscope.

\section{Elisa}

GPNMB levels were measured in human and mouse brain tissue, mouse spinal cord tissue and in human CSF and serum samples using commercially available mouse (DY2330) or human Osteoactivin/GPNMB ELISA (DY2550) sets according to the manufacturer's instructions (R\&D systems, Abingdon, UK).

Proteins were extracted from human and mouse brain samples as well as from mouse spinal cord samples. Frozen tissue was weighed and homogenized in $0.7 \mathrm{ml}$ Tris-buffered saline (TBS) buffer $(120 \mathrm{mM} \mathrm{NaCl}, 50 \mathrm{mM}$ Tris, pH 8.0 supplemented with complete protease inhibitor cocktail (Roche Diagnostics, Indianapolis, IN, USA)), per $100 \mathrm{mg}$ tissue by using a Dounce homogenizer (800 rpm). The resulting homogenate was centrifuged at $17,000 \times g$ for $20 \mathrm{~min}$ at $4{ }^{\circ} \mathrm{C}$. The supernatant containing TBS-soluble proteins was stored at $-80^{\circ} \mathrm{C}$. The pellet was dissolved in $2 \%$ sodium dodecyl sulfate (SDS) and sonicated followed by a centrifugation step at 17,000 $\mathrm{x} g$ for $20 \mathrm{~min}$ at $4{ }^{\circ} \mathrm{C}$. The supernatant, which contained SDS-soluble proteins, was incubated with $1 \mu \mathrm{l}$ of Benzonase under rotating conditions for $10 \mathrm{~min}$ at room temperature in order to reduce viscosity and stored at $-80{ }^{\circ} \mathrm{C}$.

\section{Real-time PCR}

For real-time RT-PCR analysis, WT, 5XFAD, APP/PS1KI and APP23 mice ( $n=3-6$ per group) or RNA extracts from BV2 cells $(n=6)$ were used. For RNA isolation, deep-frozen brain hemispheres or spinal cord tissue were homogenized in TriFast reagent (Peqlab) essentially as described previously [16]. Deep frozen liver samples were homogenized in $1 \mathrm{ml}$ TriFast reagent (Peqlab) per $100 \mathrm{mg}$ tissue using a glas-teflon homogenizer. BV2 cell pellets were homogenized manually in $1 \mathrm{ml}$ TriFast reagent by repetitive pipetting. DNAse digestion and reverse transcription of the purified RNA samples were carried out according to the protocol of the manufacturer (Thermo Fisher). RT-PCR was performed using a Stratagene MX3000 Real-time Cycler. The SYBR green 
based FastStart Universal SYBR Green (Roche) containing ROX as an internal reference dye was used for amplification. Relative expression levels were calculated using the $2^{-\Delta \Delta \mathrm{Ct}}$ method and normalized to the housekeeping gene $\beta$-actin [43]. Primer sequences can be found in Additional file 2.

\section{Statistical analysis}

Differences between groups were tested by either one-way analysis of variance followed by Tukey's multiple comparisons test or unpaired $t$-tests. All data were expressed as mean \pm SD. Significance levels are indicated as follows: **:* $p<0.001 ; * * 0<0.01 ; * p<0.05$. All calculations were performed using GraphPad Prism version 6.07 for Windows (GraphPad Software, La Jolla, CA, USA).

\section{Results}

\section{GPNMB expression levels increase with disease} progression in distinct transgenic $A D$ mouse models As previously reported, we initially found GPNMB mRNA levels to be significantly up-regulated in 6-month-old APP/PS1KI mice when compared to control mice in a whole-brain deep sequencing analysis [51]. In order to test whether GPNMB mRNA up-regulation occurs during normal aging or if GPNMB expression is regulated in a disease-state dependent manner, RNA of whole brain hemispheres from 3-, 7- and 10-month-old APP/PS1KI and PS1KI control mice was extracted and GPNMB expression levels were analyzed using RT-PCR. We observed a disease-state dependent upregulation of GPNMB mRNA levels in APP/PS1KI mice but not in PS1KI mice. In good agreement with our previous study, GPNMB mRNA expression was significantly increased in 7-month-old APP/PS1KI mice compared to controls $(p<0.01)$ [51]. At 12 months of age, GPNMB expression increased even further when compared to 7-month-old APP/PS1KI mice ( $p<0.01$; Fig. 1a).
To determine whether GPNMB mRNA up-regulation also occurs in other AD mouse models, potentially indicating a general event during $\mathrm{AD}$ pathology progression, RT-PCR analyses of brain hemispheres of 3-, 7- and 12-month-old 5XFAD and age-matched WT control animals were performed. While GPNMB expression was unchanged in 3-month-old 5XFAD mice when compared to WT animals, mRNA levels were significantly upregulated at 7 months of age $(p<0.05)$. At 12 months of age, GPNMB mRNA levels in 5XFAD mice were even further increased compared to WT mice $(p<0.001)$, where no age-dependent changes were detectable (Fig. 1b). Interestingly, in APP23 mice, another frequently studied mouse model of AD, no GPNMB up-regulation was detected in 12-month-old APP23 mice as compared to WT control animals (Fig. 1c).

\section{Cellular localization and distribution of GPNMB in the CNS of AD mouse models}

Next, we aimed to investigate the cellular localization of GPNMB using double staining with cellular marker proteins such as NeuN for neurons, GFAP for astrocytes and IBA1 as a marker for microglia and macrophages. While no co-localization of GPNMB was observed with NeuN or GFAP, abundant GPNMB immunoreactivity could be detected in cells positive for the microglia/ macrophage marker IBA1 in 5XFAD mice (Fig. 2).

In order to better characterize the localization of GPNMB in the CNS of AD transgenic mice, further immunohistochemical stainings were performed in brain and spinal cord of 12-month-old 5XFAD mice compared to age-matched WT controls. In 5XFAD mice, GPNMB immunoreactivity was observed throughout the whole brain with particular abundance in regions known for high $A \beta$ plaque load in this model, such as subiculum (Fig. 3a, b), cortex or thalamus, while no signal could be detected in APP23 or WT control mice (Additional files 3,4 ). 5XFAD
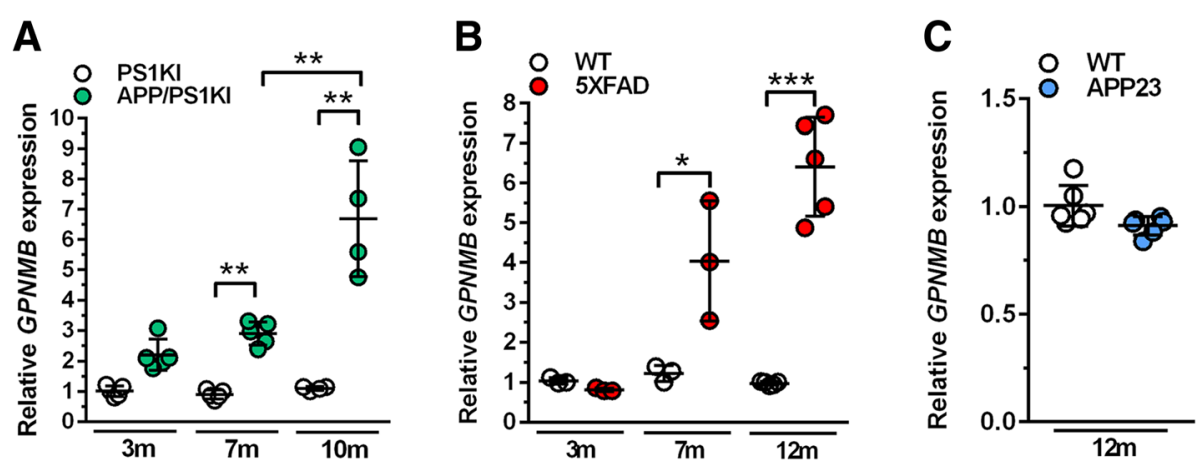

Fig. 1 GPNMB mRNA expression increases in an age- and dose-dependent manner in some Alzheimer's disease mouse models. (a) Cerebral GPNMB mRNA levels increased in an age-dependent manner in APP/PS1KI compared to PS1KI control mice. (b) In 5XFAD mice, levels of GPNMB mRNA started to be significantly increased at 7 months of age when compared to wild-type (WT) control mice. 12-month-old 5XFAD mice showed even higher GPNMB levels. (c) In 12-month-old APP23 mice, GPNMB gene expression levels were not increased compared to WT animals. All data are given as mean $\pm \mathrm{SD}$. ${ }^{* *} P<0.001$; ${ }^{*} P<0.01$; ${ }^{*} P<0.05$ 


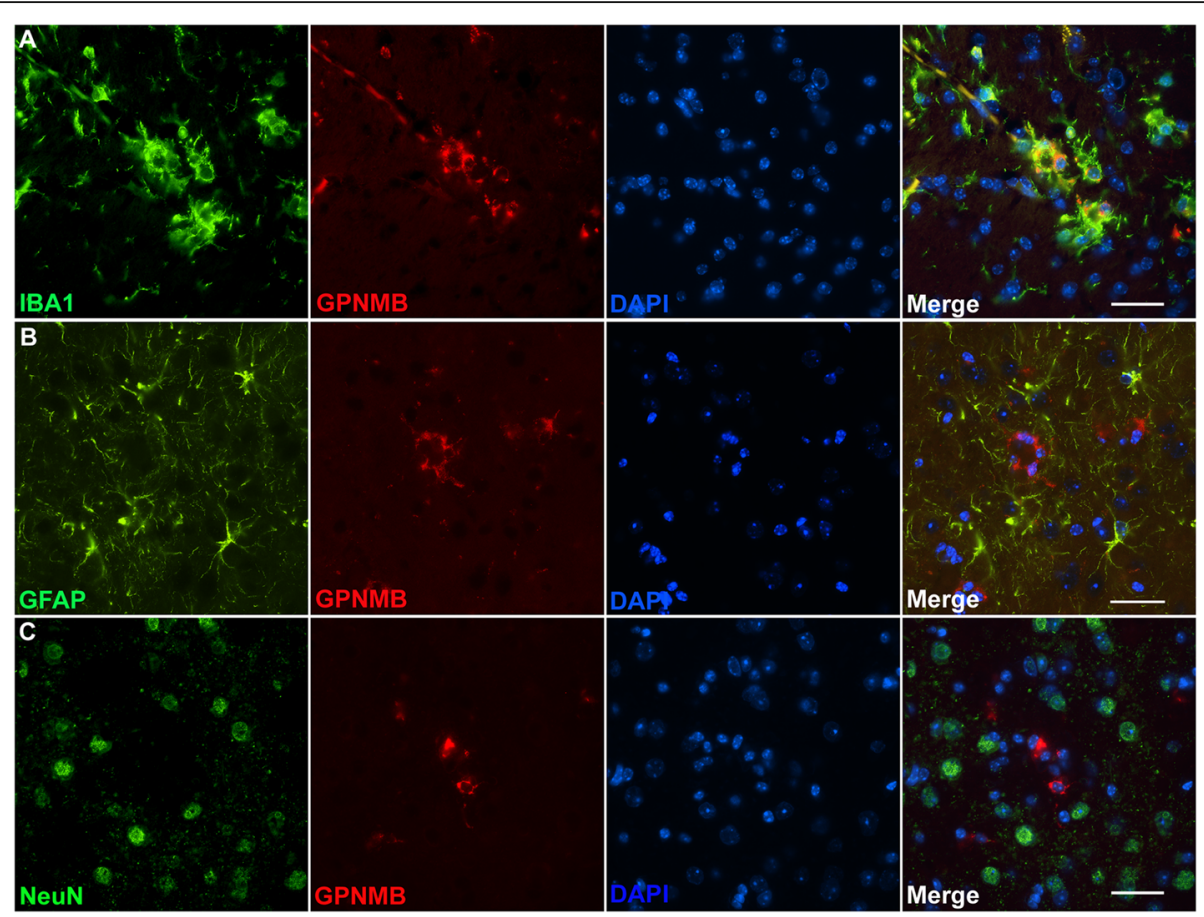

Fig. 2 GPNMB co-localizes with IBA1-positive microglia cells in 5XFAD brains. (a-c) Double immunostaining with antibodies against GPNMB and IBA1 revealed a cellular co-localization in 12-month-old 5XFAD brains, while no co-localization was seen with the astrocytic marker GFAP or the neuronal marker NeuN. Scale bar: A-C $=33 \mu \mathrm{m}$

mice start to develop amyloid pathology as early as two months of age in the subiculum and deep cortical layers. At 12 months of age, the model shows a massive $A \beta$ plaque load in various brain regions, which is accompanied by extensive astro- and microgliosis [19, 33]. To investigate whether GPNMB accumulates in parallel with amyloid plaque deposition in this model, GPNMB and $\mathrm{A} \beta$ immunoreactivity were quantified in 2.5-, 7- and 12-month-old 5XFAD mice in the cortex, subiculum, dentate gyrus and thalamus. Compared to 2.5-month-old mice, aged mice (7 m and $12 \mathrm{~m}$, respectively) revealed a significant increase in GPNMB levels in all regions analyzed. The same was true for extracellular amyloid deposition as demonstrated with antibody 24311 detecting a variety of different $A \beta$ isoforms (Additional file 3). Hence, cerebral GPNMB accumulation increases in an age-dependent manner in 5XFAD mice, resembling $\beta$-amyloid accumulation.

In order to more accurately quantify whether the increased GPNMB mRNA expression in the brains of 5XFAD mice correlated with an elevation in GPNMB protein levels, a sandwich ELISA was used to measure GPNMB levels in TBS-soluble and SDS-soluble brain fractions from both 5XFAD and APP23 mice. Analysis of 12-month-old 5XFAD mice revealed a highly significant elevation of GPNMB protein levels when compared to age-matched WT or APP23 mice $(p<0.001)$. A similar pattern was seen in the SDS-soluble fraction, showing significantly increased GPNMB protein levels in 12 -month-old 5XFAD mice $(p<0.001)$ when compared to age-matched WT or APP23 animals, respectively (Fig. 3c). These measurements also confirmed that GPNMB protein levels were not increased in 12-month-old APP23 mice as compared to WT control animals.

As GPNMB has been previously implicated in motor neuron diseases [4], spinal cord samples from aged 5XFAD mice were analyzed where $A \beta$ pathology has been previously demonstrated [19]. As seen in the brain, abundant GPNMB-immunoreactivity was observed throughout the whole spinal cord, largely resembling the IBA1 staining profile (Fig. 3d). Furthermore, a comparison of GPNMB mRNA expression levels in the spinal cord revealed a highly significant increase in 5XFAD compared to age-matched WT mice $(p<0.001)$. Liver samples were used as a control peripheral tissue and did not show any induction of GPNMB levels in aged 5XFAD mice (Fig. 3e). Likewise, protein extracts from 5XFAD and age-matched WT spinal cord samples revealed a significant elevation of GPNMB protein levels in both TBS- and SDS-soluble spinal cord fractions of 5XFAD mice ( $p<0.001$, respectively) (Fig. 3f). For a subset of analyzed animals, both RNA and protein samples from the same mouse was available. Statistical analysis revealed a high correlation for GPNMB RNA and protein levels (Additional file 5). 


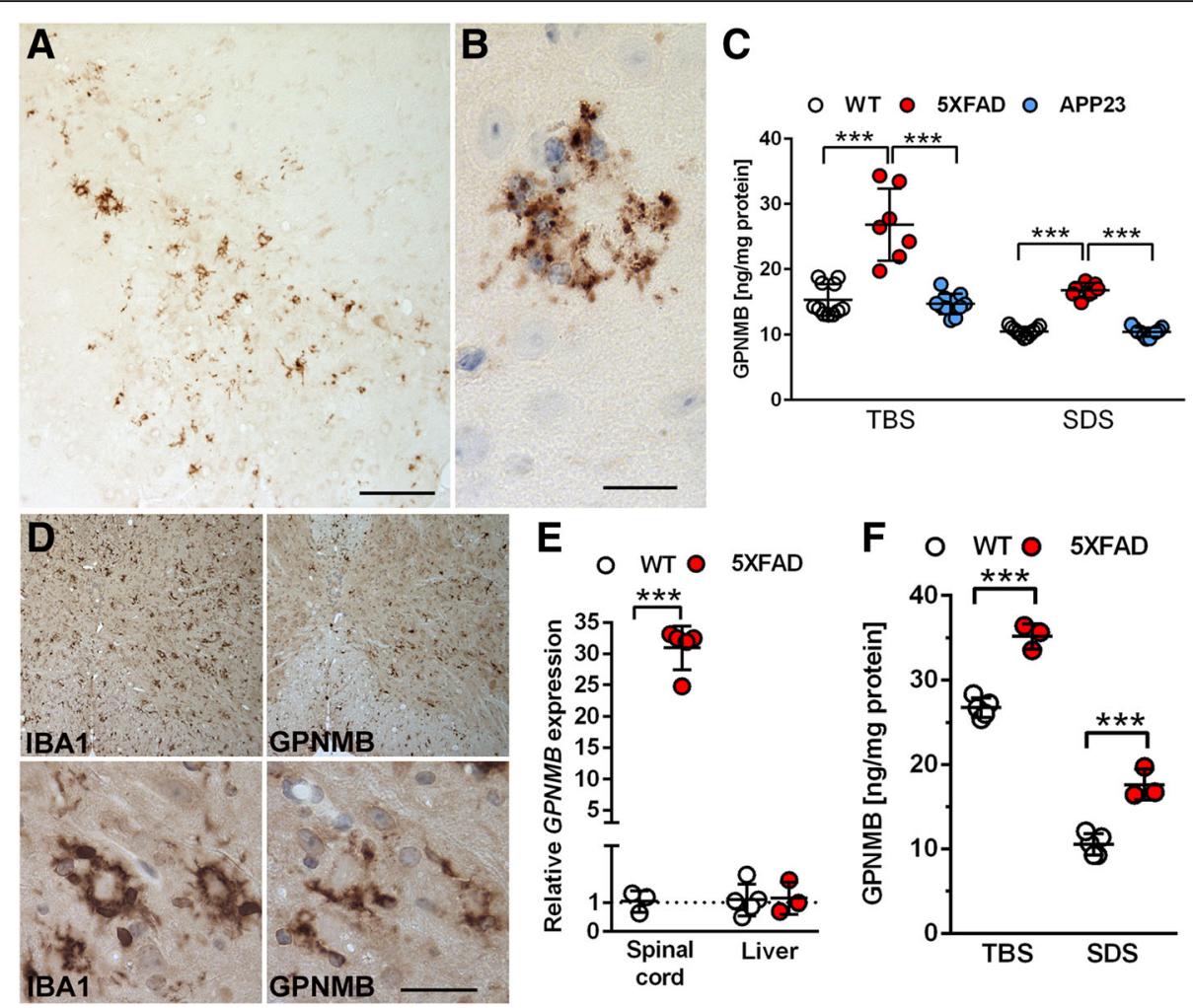

Fig. 3 Increased GPNMB protein levels and cerebral expression pattern in 5XFAD mice. (a) Abundant GPNMB staining was detected throughout the whole brain in 12-month-old 5XFAD mice, e.g. in the subiculum. (b) High-power view of GPNMB-positive cells surrounding an amyloid plaque core. (c) Quantitative analysis of GPNMB protein levels in TBS- and SDS-soluble brain fractions of 12-month-old WT, 5XFAD and APP23 mice revealed a highly significant increase in GPNMB levels in 5XFAD mice compared to WT animals, while no elevated levels could be observed in APP23 mice. (d) GPNMB immunoreactivity was also demonstrated in the spinal cord (SC) of 12-month-old 5XFAD mice. GPNMB was abundantly expressed throughout the whole SC tissue and showed co-localization with IBA1-positive microglia cells (parallel sections). (e) As demonstrated by RT-PCR analyses, 5XFAD mice showed a highly significant increase in GPNMB mRNA levels in the SC when compared to WT controls. However, no such differences were observed in peripheral liver samples serving as a non-neuronal control tissue. Enzyme-linked immunosorbent assay revealed highly increased GPNMB protein level in 5XFAD SC tissue compared to WT controls (f). All data are given as mean \pm SD. ${ }^{* * *} P<0.001$. Scale bar: $A=133 \mu \mathrm{m}, B=25 \mu \mathrm{m} ; \mathrm{D}=200 \mu \mathrm{m}$ (upper panel), $20 \mu \mathrm{m}$ (lower panel)

As GPNMB immunoreactivity was mainly present in brain areas known for robust amyloid deposition in 5XFAD mice, co-immunofluorescence stainings for GPNMB, IBA1 and $\mathrm{A} \beta$ were performed in 12-month-old animals in order to study spatial co-localization. Triple-labeling with GPNMB (red), IBA1 (green) and pan-A $\beta$ (magenta) demonstrated that GPNMB protein was mainly detectable around amyloid plaque cores (Fig. 4a-d). In order to further investigate whether elevated GPNMB expression is a common phenomenon in $\mathrm{AD}$ transgenic mice, 12-month-old APP23 were analyzed using immunohistochemistry. Although abundant IBA1-positive microglia surrounded extracellular A $\beta$ deposits in both 5XFAD and APP23 mice, GPNMB-immunoreactivity was restricted to the 5XFAD model, where it clustered around the central dense plaque core (Additional file 6) with microglia being consistently negative in 12-month-old APP23 mice (Fig. 4e-h and Additional file 4).

\section{GPNMB expression correlates with markers for} disease-associated microglia

We further analyzed markers that have been proposed to be indicative of a subgroup of microglia cells under disease conditions, so called disease-associated microglia (DAMs) or microglial neurodegenerative phenotype (MGnD), but are absent or scarcely expressed in healthy animals [22, 24]. Indeed, levels of genes such as CST7, TREM2, APOE, $C L E C 7 a$ or $C C L 2$ were found significantly up-regulated in 12-month-old 5XFAD mice compared to both WT and APP23 mice, while levels of homeostatic microglia genes like AIF1 or TMEM119 were unchanged (Fig. 4i). Significant correlations between GPNMB and CST7, AIF1, TREM2, APOE, CLEC7a and CCL2 were observed while no correlation could be detected between GPNMB and the homeostatic microglia marker TMEM119 (Additional file 7).

Next, we assessed whether $A \beta$ peptides were able to trigger $G P N M B$ expression in vitro. To this end, the 

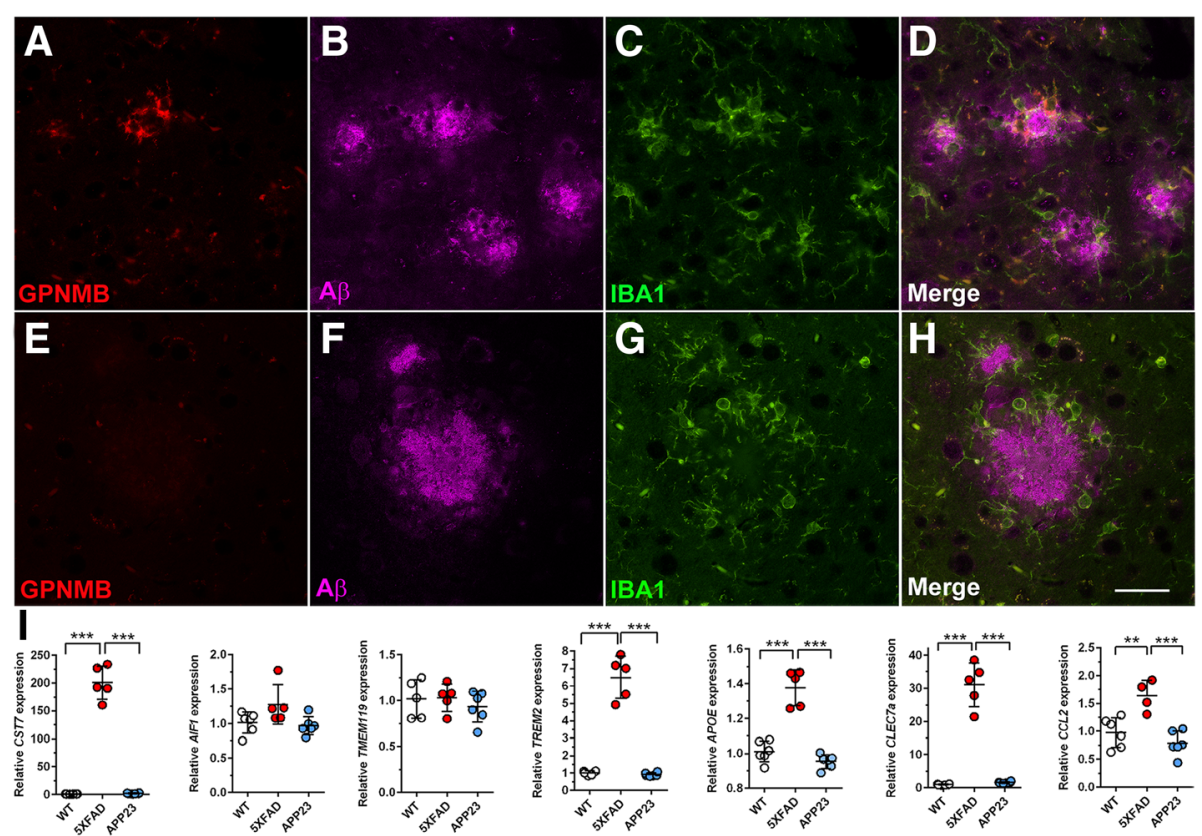

Fig. 4 GPNMB/IBA-1-positive microglia cells cluster around individual plaque cores in 5XFAD brains. Triple immunofluorescence staining using antibodies against GPNMB (a), A $(\mathbf{b})$ and IBA1 (c) demonstrated the spatial co-localization of GPNMB-positive microglia cells around amyloid plaque cores in 12-month-old 5XFAD brains (d). Even though APP23 mice showed numerous activated microglia cells (g) clustered around amyloid plaques (f), no GPNMB signal could be detected (e,h). (i) RT-PCR analyses revealed significantly increased mRNA levels of CST7, TREM2, APOE, CLEC7A and CCL2 in 5XFAD brains when compared to WT and APP23 mice. However, levels of AIF1 and TMEM119 were comparable in all groups tested. All data are given as mean \pm SD. ${ }^{* *} P<0.001 ;{ }^{* * P}<0.01$. Scale bar: A-H $=33 \mu \mathrm{m}$

immortalized murine microglial cell line BV-2 was treated with $5 \mu \mathrm{M}$ synthetic $\mathrm{A} \beta_{1-42}$ or conditioned medium derived from SH-SY5Y cells overexpressing human APP695 with the Swedish mutation. This medium was harvested after $48 \mathrm{~h}$ and contained mainly $\mathrm{A} \beta_{1-40}$ and $A \beta_{1-42}$ (Additional file 8). Treatment with LPS was employed as a control condition to trigger an inflammatory reaction. Quantification of mRNA expression levels revealed a significant up-regulation of GPNMB in cells treated with $A \beta_{1-42}$ or $A \beta$-conditioned medium while LPS treatment did not change GPNMB expression (Fig. 5a). Instead, LPS treatment led to a typical microglia activation pattern as indicated by up-regulation of genes encoding for pro-inflammatory cytokines such as $I L-1 \beta$ and TNF (Fig. 5b-c). CLEC7A and APOE representing DAM markers showed a significantly increased expression only after treatment with conditioned medium containing A $\beta$ peptides (Fig. $5 \mathrm{~d}$-e). Surprisingly, the expression levels of the transcription factor MITF, which has been reported as an important regulator of GPNMB [9], was unchanged in conditions with elevated GPNMB expression (Fig. 5f).

\section{GPNMB in sporadic Alzheimer's disease cases}

Finally, we investigated whether our findings in mouse models of $\mathrm{AD}$ can be translated to human $\mathrm{AD}$ patients. Thus, brain samples from AD and NDC subjects were stained with a GPNMB antibody. The specificity of the antibody used for immunohistochemical staining of human brain tissues was verified with a blocking peptide which entirely abolished GPNMB immunoreactivity (Additional file 9). Interestingly, abundant GPNMB immunoreactivity was observed throughout cortical tissue samples from sporadic AD patients. In particular, intense GPNMB staining was detected in vessel walls and around amyloid plaque cores, confirming our observations in AD mouse models (Fig. 6a, b, e). However, also non-plaque-associated GPNMB-positive cells were frequently detected showing an amoeboid phenotype reminiscent of lipid-laden microglia in tissue samples from human patients (Fig. 6c, f). In non-demented controls, considerably less GPNMB immunoreactivity was observed and only occasionally GPNMB-positive cells were detected throughout the cortex (Fig. 6d).

We next measured TBS- and SDS-soluble GPNMB protein levels in lysates of the medial frontal gyrus of human patients with sporadic $\mathrm{AD}$ and non-demented controls. Quantification using a GPNMB-specific sandwich ELISA revealed that TBS-soluble GPNMB protein levels tended to be increased in $\mathrm{AD}$ patients in comparison to non-demented control individuals, but the difference did not reach statistical significance ( $p=0.06$; Fig. $6 \mathrm{~g})$. In the SDS-soluble fraction, no difference in GPNMB protein levels was noted between the two groups (Fig. 6h). 
A

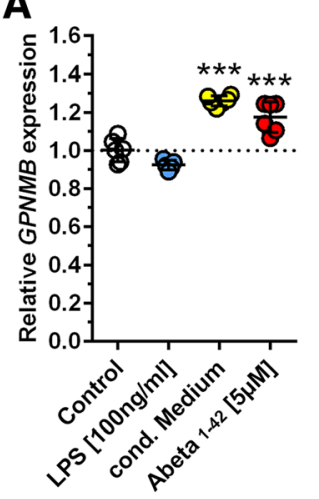

D

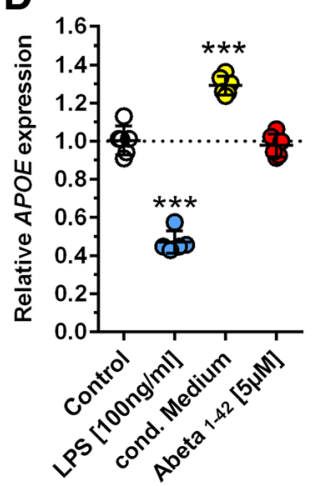

B

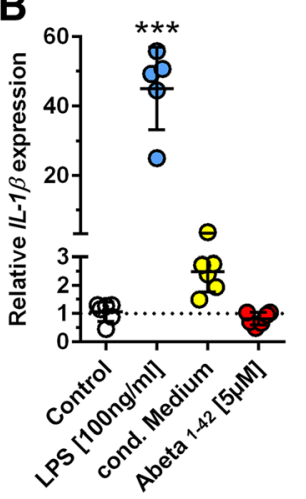

E

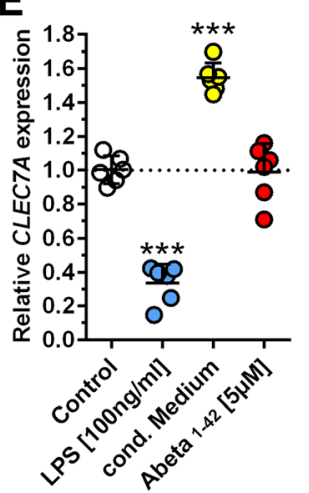

C

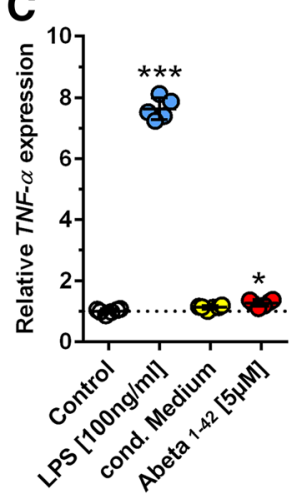

$\mathbf{F}$

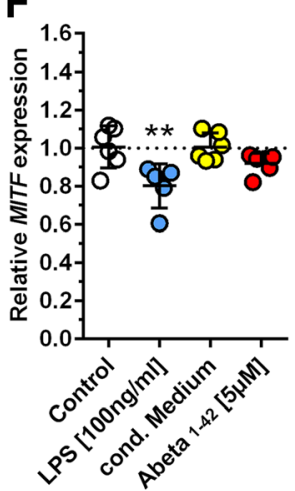

Fig. 5 Soluble A $\beta$ induces GPNMB mRNA expression in immortalized microglia cells. (a) Treatment of BV2 cells with A -containing medium or synthetic $A \beta_{1-42}$ peptides resulted in a highly significant increase in GPNMB mRNA expression, while LPS treatment had no effect on GPNMB levels. In contrast, LPS treatment caused microglia activation as shown by upregulation of the pro-inflammatory cytokines IL1- $\beta$ and TNFa (b, c). While LPS treatment led to decreased expression of APOE and CLEC7A, conditioned A $\beta$-containing media induced these DAM phenotypeassociated genes ( $\mathbf{d}, \mathbf{e})$. MITF levels did not change following treatment with $A \beta$-conditioned medium or synthetic $A \beta$ although GPNMB levels were clearly elevated $(\mathbf{f})$. All data are given as mean \pm SD. ${ }^{*} P<0.05$; ${ }^{* *} P<0.01$; ${ }^{* *} P<0.001$

In addition, GPNMB protein levels were measured in the CSF and sera of a distinct cohort of patients suffering from sporadic AD as well as in non-demented controls. Importantly, GPNMB protein levels were found to be significantly increased in the CSF of sporadic AD patients when compared to non-demented controls $(p<$ 0.05). (Fig. 6i). No differences in GPNMB levels between non-demented controls and sporadic AD patients were found in serum samples (Fig. 6j). In order to validate the GPNMB ELISA measurements presented in the current study intra-assay coefficients of variation (relative standard deviations) between duplicate reads (technical replicates on the same assay plate) were calculated for the different sample matrices and are summarized in Additional file 10. In addition, TBS- and SDS-soluble brain extracts from WT mice $(n=11)$ were measured on 2 different days. The mean inter-assay coefficients of variation were $4.7 \%$ (median $3.4 \%$, range $0.8-19.9 \%$ ) for TBS- and 15.7\% (median 16.8\%, range $8.9-20.3 \%$ ) for SDS-soluble fractions.

\section{Discussion}

Since therapeutic approaches against long established AD targets such as amyloid plaques and NFTs have so far not been successful, more recent therapeutic strategies try to tackle alternative targets, among which neuroinflammation is one of the most promising. Accumulating evidence suggests a critical role for microglia in the pathogenesis of $\mathrm{AD}$, and latest human genetics data have identified several novel AD risk genes such as CD33 or CR1, which are highly expressed by these brain resident immune cells (reviewed in [21]). Two main hypotheses have been put forward regarding the role of reactive microglia in brain diseases. One is claiming that microglia is protective against CNS insults such as aggregated $\beta$-amyloid by promoting their clearance through phagocytosis. On the other hand, many findings indicate that chronic activation of microglia is harmful to neurons and contributes to disease progression and severity. In $\mathrm{AD}$, while the detrimental effects of microglia activation seem to manifest in later stages of the 


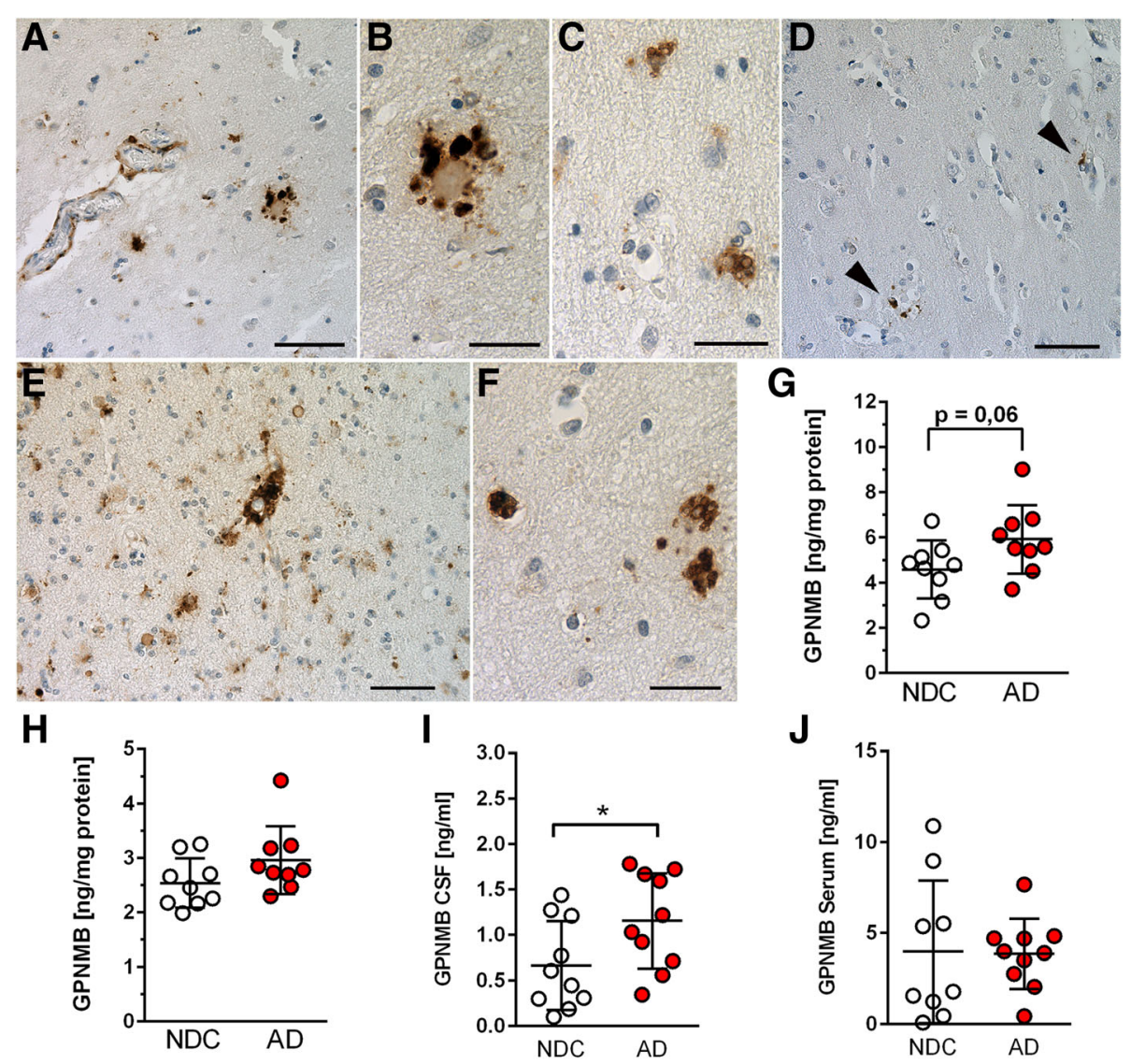

Fig. 6 Increased GPNMB protein levels in brain tissue and cerebrospinal fluid (CSF) of sporadic Alzheimer's disease cases. GPNMB immunoreactivity was detected in microglial cells surrounding amyloid plaque cores and in the vicinity of blood vessel walls (a, e). (b) High-power view of the plaque core in (a). In addition, GPNMB-positive amoeboid microglia were detected in plaque-free areas (c, $\mathbf{f}$ ), while GPNMB-positive microglia were only occasionally observed in samples from non-demented control patients $(\mathbf{d})$. (g) In the TBS-soluble brain fractions, higher levels of GPNMB were detected in AD cases when compared to non-demented controls (NDC), however, without reaching statistical significance $(p=0.06)$. (h) No differences were detected between the two groups in SDS-soluble brain fractions. (i) The amount of GPNMB in the CSF of AD patients was significantly higher than in control patients. (j) No significant difference in GPNMB serum levels could be detected between controls and AD. All data are given as mean \pm SD. ${ }^{*} P<0.05$. Scale bar: $A, D, E=50 \mu m ; B, C, F=20 \mu m$

disease, protective microglial activities supposedly occur in the early disease stages [10]. In order to develop therapeutic approaches that target microglia and modulate their behaviour, a better understanding of the proteins and molecular mechanisms involved in their activation and potential dysfunction in $\mathrm{AD}$ brains is required.

In our recent transcriptome analysis of the APP/PS1KI transgenic AD mouse model, which develops severe neurodegeneration, a variety of genes implicated in the neuroinflammatory response were identified as overexpressed [51]. One of the most strongly up-regulated genes was GPNMB, a transmembrane type I protein also known as osteoactivin. We here describe GPNMB as a novel AD-associated marker in both transgenic $\mathrm{AD}$ models and sporadic $\mathrm{AD}$ patients. Using immunohistochemical analyses, RT-PCR experiments and ELISA measurements, we were able to show that $G P N M B$ is overexpressed in the APP/PS1KI and
5XFAD transgenic mouse models of $\mathrm{AD}$ in an age-dependent manner, with age-matched WT animals being consistently negative. Double-immunofluorescent staining using GPNMB and the microglia/macrophage marker IBA1 revealed a distinct co-localization, corroborating previous results in the inflamed rat brain, where GPNMB was found to co-localize with the microglia/macrophage marker OX42 [15]. Co-stainings with markers against GFAP to detect astrocytes or NeuN to detect neurons were consistently negative, underscoring the restricted microglial localization. This result is also in good agreement with recent data from a RNA-sequencing study, which demonstrated GPNMB expression primarily in microglia and, to a lesser extent, in oligodendrocyte precursor cells [60]. It is further supported by a recent transcriptome study demonstrating an upregulation of GPNMB in major histocompatibility complex (MHC) II-positive microglial cells isolated from the 5XFAD mouse model [58]. 
Employing multi-fluorescent staining using antibodies against GPNMB, IBA1 and $A \beta$, we found that GPNMB-positive microglia were primarily located in the close vicinity of extracellular plaques in the 5XFAD mouse model. In contrast, no GPNMB-immunoreactivity could be detected in APP23 mice, although this model also showed abundant extracellular plaque pathology surrounded by numerous IBA1-positive microglia cells [45]. This is also reflected in an earlier RNA microarray analysis of APP23 mice, in which no overexpression of GPNMB was reported [49]. In contrast, GPNMB was found to be up-regulated in a longitudinal gene profiling analysis of the 5XFAD mouse model [27], as well as in a transcriptome study investigating gene expression changes in CD11c-positive microglia isolated from the amyloid-depositing APPswe/PS1dE9 mouse model [20,35]. While 5XFAD mice show cortical neuron loss at 12 months of age [7, 19], even higher cortical neuron numbers have been reported in 8-month-old APP23 compared to WT mice, which decrease in 27-month-old APP23 mice back to WT levels [2]. In addition, the amyloid plaque composition in APP23 mice is much different compared to human $A D$ with $A \beta_{1-40}$ representing the main component in APP23 while $A \beta_{1-42}$ is the predominant species in human $\mathrm{AD}$ brain [42].

Activated microglia are characteristic for numerous neurodegenerative diseases aside from $\mathrm{AD}$ [50]. Studies integrating microglial/myeloid expression data sets from diverse neurodegenerative disease models, including $\mathrm{AD}$ transgenic mice, multiple sclerosis and ALS models, have suggested the presence of a particular microglia activation state, which has been termed either "microglial neurodegenerative phenotype" (MGnD) [24] or "disease-associated microglia" (DAM) [22]. Together with other genes (e.g. CLEC7A, CCL2 or FABP5), GPNMB was found to be up-regulated in the MGnD profile. In addition, it has been proposed that Trem 2 and ApoE are intimately linked to a switch from a homeostatic to a neurodegenerative microglial phenotype [24]. Based on these findings, we tested whether other MGnD genes might be induced in 5XFAD mice with elevated GPNMB levels, but not in APP23 mice, in which GPNMB expression was not increased. Indeed, the strong transcriptional activation of GPNMB and CST7 in 12-month-old 5XFAD but not in APP23 mice, together with the unchanged expression levels of the microglia homeostatic genes AIF1 and TMEM119 was consistent with the idea that GPNMB might be regulated as part of the MGnD response. The exact role of the MGnD activation state is not clear. However, it has been shown that the injection of apoptotic neurons into the cortex and hippocampus of adult mice resulted in the induction of $A P O E$ and the up-regulation of other genes implicated in the MGnD profile, including GPNMB [24]. APOE expression was also up-regulated in our 5XFAD but not in the APP23 mice, together with additional MGnD-associated markers such as CLEC7A or CCL2. This could mean that the MGnD activation state is only triggered in the presence of dead or dying neurons, and fits well to the observation of abundant GPNMB-immunoreactivity in 5XFAD mice. In contrast to APP23 mice, which show no neocortical neuron loss even at 27 months of age [2], significantly reduced neuron numbers have been reported in deep cortical layers of 5XFAD mice beginning at nine months of age $[7,19,54]$. Similarly, APP/PS1KI mice also show a strong age-dependent induction of GPNMB expression, together with the up-regulation of several MGnD-associated genes such as CLEC7A, ITGAX or CSF1 [51] and with robust hippocampal and cortical neuron loss $[3,6]$.

Additionally, we provide in vitro evidence that soluble $A \beta$ might promote the switch in microglia gene expression from a "homeostatic" to a "disease-associated" state. Upon treatment of an immortalized microglial cell line with synthetic $A \beta_{1-42}$ or $A \beta$-containing conditioned media, the expression levels of GPNMB as well as other MGnD-associated markers such as $A P O E$ and $C L E C 7 A$ were highly increased. This indicates that soluble $A \beta$ peptides are also capable of inducing GPNMB expression, in addition to aggregated $A \beta$ as found in brain tissues from human $\mathrm{AD}$ or transgenic $\mathrm{AD}$ mice. In contrast, treatment of microglia cells with LPS induced a typical pro-inflammatory gene expression profile, with $G P N M B$ levels being unchanged. Surprisingly, expression levels of the transcription factor MITF, which has been reported to be a critical regulator of GPNMB expression [9], was found to be down-regulated following LPS treatment. However, it has also been shown that LPS is capable of suppressing gene expression in macrophages by down-regulating factors such as MITF [18].

We suggest that $A \beta$ itself could be partially responsible for the phenotypic switch of microglia to a neurodegenerative state during $\mathrm{AD}$ progression, although it is clearly not sufficient in vivo as shown by the lack of MGnD markers in APP23 mice. In conclusion, our findings in transgenic $\mathrm{AD}$ mouse models support that GPNMB is part of a microglial activation state that occurs in advanced disease stages and only in $\mathrm{AD}$ models showing profound cerebral neuron loss. Besides elevated GPNMB levels, this microglial activation state under neurodegenerative conditions is characterized by the upregulation of a subset of genes including APOE, TREM2, CLEC7A and CST7. Whether GPNMB has a protective or detrimental role in this context has to be elucidated, but available in vitro evidence would argue for an anti-inflammatory, regenerative role of GPNMB [32, 39, 59, 61] (Fig. 7).

Importantly, we also found GPNMB to be elevated in both brain tissue and CSF samples of sporadic AD patients. To the best of our knowledge, the current study is the first to report elevated GPNMB levels in human AD subjects. At present, due to the small group sizes, the current results have to be interpreted with caution. Further studies with 


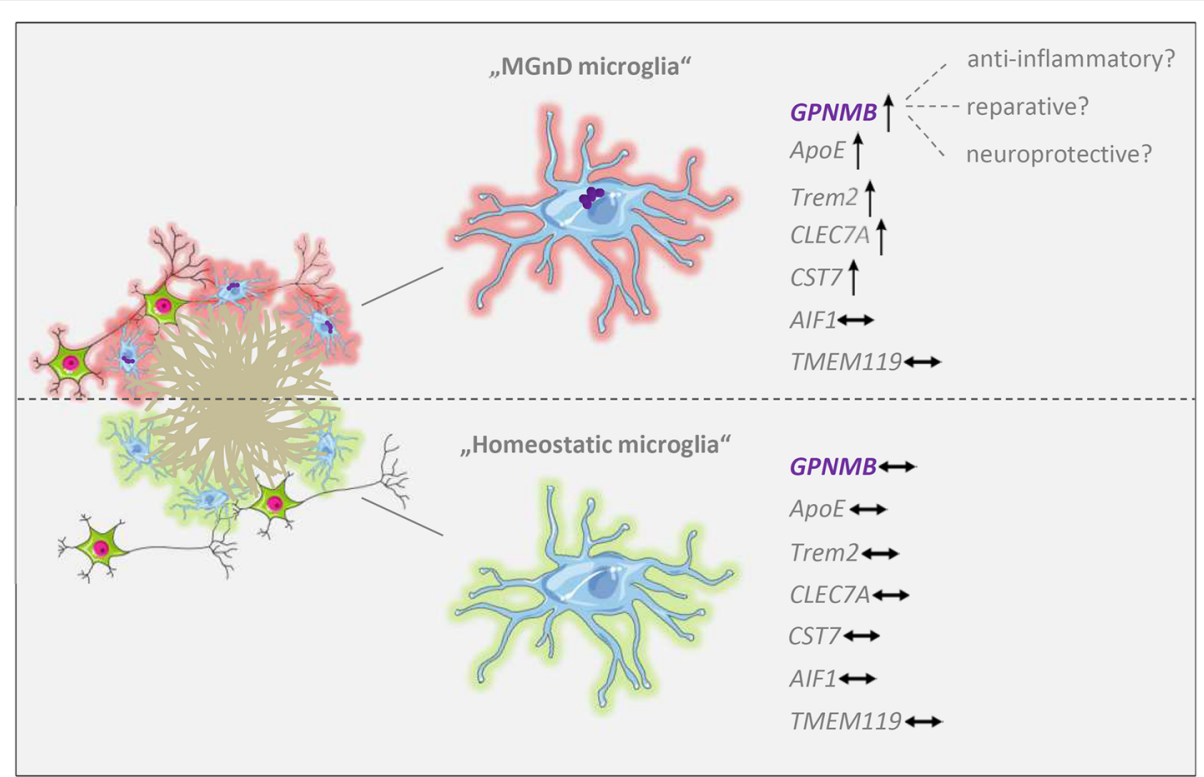

Fig. 7 Schematic summary of results and hypothesis: In Alzheimer's disease (AD) mouse models with profound neuron loss (e.g. 5XFAD), GPNMBpositive activated microglia cells cluster around individual amyloid plaque cores. In contrast, microglia cells are persistently GPNMB-negative in healthy wild-type mice or AD models showing abundant plaque pathology without neuron loss. Under neurodegenerative conditions, microglia switch from a homeostatic to a disease-associated phenotype, which has been called "microglial neurodegenerative phenotype" (MGnD) or "disease-associated microglia" (DAMs), and which is characterized by the upregulation of a subset of genes including GPNMB. The precise role of GPNMB in the central nervous system is not yet known, however, evidence indicates that it has anti-inflammatory and regenerative functions. Individual components of the scheme have been taken from: http://smart.servier.com

larger cohorts will be required to confirm these observations. Nevertheless, our findings are partially similar to studies of TREM2, which has been proposed as a potential microglia-associated biomarker for $\mathrm{AD}$ progression and therapy monitoring. TREM2 is also a type-I transmembrane protein localized to the cell surface that can undergo ectodomain shedding by ADAM proteases, and soluble TREM2 (sTREM2) has been detected in body fluids including the CSF. Although not consistent between all published studies, elevated sTREM2 levels have been reported in CSF samples of sporadic $\mathrm{AD}$ patients versus non-demented controls [11, 12, 36, 47]. Taken together, these studies provide proof of concept evidence that a microglia-derived protein that is detectable in body fluids like TREM2 or GPNMB could be used as a biomarker to monitor disease onset and progression, and might even function as a prognostic marker.

Elevated GPNMB levels were also reported in several other neurodegenerative disorders apart from $\mathrm{AD}$. In patients with sporadic ALS, a disease characterized by the degeneration of motor neurons in the cerebral cortex and spinal cord, extracellular GPNMB aggregates were found in the grey and white matter of spinal cord tissue [30]. Consistent with this finding, the same group reported increased levels of GPNMB in the CSF and serum of ALS patients [48]. Elevated levels of GPNMB have also been shown in brains, CSF and plasma of Gaucher disease patients [23, 62]. Furthermore, the glycoprotein has been reported to be increased in Niemann-Pick Type C disease as well as in Tay-Sachs- and Sandhoff disease [28]. These diseases belong to the group of lysosomal storage disorders (LSDs), which are characterized by the abnormal accumulation of cellular debris in lysosomes and subsequent neurodegeneration [37]. Interestingly, a two-stage genome-wide association (GWA) meta-analysis associated GPNMB with a higher risk for Parkinson's disease (PD) [17]. However, follow-up studies with independent cohorts of patients did not corroborate these initial findings [56, 57]. Given the involvement of GPNMB in other neurodegenerative diseases besides $\mathrm{AD}$, it is unlikely to serve as a disease-specific biomarker. However, this does not exclude the possibility that multiplexing putative microglia-derived markers such as TREM2 and GPNMB with other proteins that might be discovered in future studies could result in disease-specific marker signatures. Apart from that, CSF GPNMB levels could potentially be used to monitor disease progression. In mice, we could demonstrate that GPNMB levels increased with age and disease progression. As the transgenic mouse models employed in the current study address in particular amyloid pathology, other models reflecting further pathological hallmarks have to be considered in future studies. In addition, longitudinal studies will be required to translate these findings into human patients and to prove that GPNMB levels correlate with the onset and course of human AD. 


\section{Conclusions}

Finally, as GPNMB has been shown to negatively regulate inflammatory responses [39], it is tempting to speculate that the protein is induced in neurodegenerative conditions such as AD or LSDs to restrain inflammation and to protect neurons. Therefore, increasing GPNMB levels in the CNS might be a potential future therapeutic strategy. However, more research to elucidate the precise role of GPNMB in the inflammatory responses associated with neurodegenerative diseases is clearly required.

\section{Additional files}

Additional file 1: Characteristics of the study cohorts used for ELISA

Additional file 2: List of primers used for quantitative Real-Time PCR. (PDF $153 \mathrm{~kb}$ )

Additional file 3: Quantification of $A B$ plaque load and GPNMB immunoreactivity in 5XFAD mice. (PDF $434 \mathrm{~kb}$ )

Additional file 4: Immunostaining against $A \beta$ and GPNMB in paralle sections in the cortex of a 12-month-old APP23 mouse. (PDF $285 \mathrm{~kb}$ )

Additional file 5: Correlation analysis between GPNMB-ELISA (TBS- and SDSsoluble fractions) and GPNMB expression levels measured by RT-PCR (PDF $30 \mathrm{~kb}$ )

Additional file 6: High magnification of an amyloid plaque surrounded by GPNMB-positive microglia. (PDF $481 \mathrm{~kb}$ )

Additional file 7: Correlation analysis between GPNMB gene expression levels and microglia markers measured by RT-PCR. (PDF $121 \mathrm{~kb}$ )

Additional file 8: SDS-PAGE and Western-blot of $A \beta$ peptides from the supernatant of APP695sw-transfected SH-SY5Y cells. (PDF 207 kb)

Additional file 9: Peptide competition assay to block GPNMB immunoreactivity in immunohistochemical stainings. (PDF $190 \mathrm{~kb}$ )

Additional file 10: Intra-assay variation of the ELISA measurements of the different sample matrices. (PDF $106 \mathrm{~kb}$ )

\section{Funding}

Oliver Wirths is supported by the Alzheimer Forschung Initiative (grant 16013) and Gerhard-Hunsmann-Stiftung. The study was also supported by grants from the German Federal Ministry of Education and Research (project FILDc 01G1007A, the EU Joint Programme-Neurodegenerative Diseases networks PreFrontAls (01ED1512) and the foundation of the state of Baden-Wuerttemberg (D.3830) and BIU (D.5009) to Markus Otto. Jens Wiltfang is supported by an llídio Pinho professorship and iBiMED (UID/BIM/04501/2013) at the University of Aveiro, Portugal. Figure 7 was modified from Smart Servier Medical Art website (https://smart.servier.com), licensed under a Creative Common Attribution 3.0 Unported License.

\section{Availability of data and materials}

All data generated or analyzed during this study are included in this published article and its Additional files 1, 2, 3, 4, 5, 6, 7, 8, 9, 10.

\section{Author contributions}

$\mathrm{MH}$ performed experiments, analyzed data and wrote the manuscript. 10 performed experiments, $\mathrm{MO}$ and JW provided reagents and samples and HK, CS and SW analyzed data and contributed to the interpretation of findings and revision of the manuscript. OW designed the study, performed experiments, analyzed data and wrote the manuscript. All authors read and approved the final manuscript.

\section{Ethics approval and consent to participate}

All procedures involving human tissue have been approved by the ethical committee of the University Medical Center Göttingen (Ethical approval 12/1/15). All tissues have been received from the Netherlands Brain Bank (NBB) or the Dept. of Neurology at University of Ulm (Ethical approval 20/10) and all material and data collected are obtained on the basis of written informed consent. All experimental procedures in the study that involved animals were approved by the institutional animal care and use committee at University Medicine Göttingen.
Consent for publication

All authors have given consent for publication.

\section{Competing interests}

The authors declare that they have no competing interests.

\section{Publisher's Note}

Springer Nature remains neutral with regard to jurisdictional claims in published maps and institutional affiliations.

\section{Author details}

${ }^{1}$ Department of Psychiatry and Psychotherapy, University Medical Center (UMG), Georg-August-University, Von-Siebold-Str. 5, 37075 Göttingen, Germany. ${ }^{2}$ Department of Neuropathology, Heinrich-Heine-University, Düsseldorf, Germany. ${ }^{3}$ Department of Neurology, University of UIm, UIm, Germany. ${ }^{4}$ Department of Neuropathology, University Medical Center, Georg-August-University, Göttingen, Germany. ${ }^{5}$ German Center for Neurodegenerative Diseases (DZNE), Göttingen, Germany.

Received: 28 August 2018 Accepted: 2 October 2018

Published online: 19 October 2018

\section{References}

1. Abdelmagid SM, Barbe MF, Rico MC, Salihoglu S, Arango-Hisijara I, Selim AH, Anderson MG, Owen TA, Popoff SN, Safadi FF (2008) Osteoactivin, an anabolic factor that regulates osteoblast differentiation and function. Exp Cell Res 314:2334-2351

2. Bondolfi L, Calhoun M, Ermini F, Kuhn HG, Wiederhold KH, Walker L, Staufenbiel M, Jucker M (2002) Amyloid-associated neuron loss and gliogenesis in the neocortex of amyloid precursor protein transgenic mice. J Neurosci 22:515-522

3. Breyhan H, Wirths O, Duan K, Marcello A, Rettig J, Bayer TA (2009) APP/PS1KI bigenic mice develop early synaptic deficits and hippocampus atrophy. Acta Neuropathol 117:677-685

4. Budge KM, Neal ML, Richardson JR, Safadi FF (2018) Glycoprotein NMB: an emerging role in neurodegenerative disease. Mol Neurobiol 55:5167-5176

5. Casas C, Sergeant N, Itier JM, Blanchard V, Wirths O, van der Kolk N, Vingtdeux $V$, van de Steeg E, Ret G, Canton T et al (2004) Massive CA1/2 neuronal loss with intraneuronal and $\mathrm{N}$-terminal truncated Abeta42 accumulation in a novel Alzheimer transgenic model. Am J Pathol 165:1289-1300

6. Christensen DZ, Kraus SL, Flohr A, Cotel MC, Wirths O, Bayer TA (2008) Transient intraneuronal Abeta rather than extracellular plaque pathology correlates with neuron loss in the frontal cortex of APP/PS1KI mice. Acta Neuropathol 116:647-655

7. Eimer WA, Vassar R (2013) Neuron loss in the 5XFAD mouse model of Alzheimer's disease correlates with intraneuronal Abeta42 accumulation and Caspase-3 activation. Mol Neurodegener 8:2

8. Guerreiro R, Wojtas A, Bras J, Carrasquillo M, Rogaeva E, Majounie E, Cruchaga C, Sassi C, Kauwe JSK, Younkin S et al (2013) TREM2 variants in Alzheimer's disease. N Engl J Med 368:117-127

9. Gutknecht M, Geiger J, Joas S, Dörfel D, Salih HR, Müller MR, Grünebach F, Rittig SM (2015) The transcription factor MITF is a critical regulator of GPNMB expression in dendritic cells. Cell Communication and Signaling 13:19

10. Hansen DV, Hanson JE, Sheng M (2018) Microglia in Alzheimer's disease. J Cell Biol 217:459-472

11. Henjum K, Almdahl IS, Årskog V, Minthon L, Hansson O, Fladby T, Nilsson LNG (2016) Cerebrospinal fluid soluble TREM2 in aging and Alzheimer's disease. Alzheimers Res Ther 8:17

12. Heslegrave A, Heywood W, Paterson R, Magdalinou N, Svensson J, Johansson P, Öhrfelt A, Blennow K, Hardy J, Schott J et al (2016) Increased cerebrospinal fluid soluble TREM2 concentration in Alzheimer's disease. Mol Neurodegener 11:3

13. Hollingworth P, Harold D, Sims R, Gerrish A, Lambert J-C, Carrasquillo MM, Abraham R, Hamshere ML, Pahwa JS, Moskvina V, et al: Common variants at ABCA7, MS4A6A/MS4A4E, EPHA1, CD33 and CD2AP are associated with Alzheimer\&\#39;s disease. Nat Genet 2011, 43:429

14. Hopperton KE, Mohammad D, Trépanier MO, Giuliano V, Bazinet RP (2018) Markers of microglia in post-mortem brain samples from patients with Alzheimer's disease: a systematic review. Mol Psychiatry 23:177-198 
15. Huang J-J, Ma W-J, Yokoyama S (2012) Expression and immunolocalization of Gpnmb, a glioma-associated glycoprotein, in normal and inflamed central nervous systems of adult rats. Brain and Behavior 2:85-96

16. Hüttenrauch M, Baches S, Gerth J, Bayer TA, Weggen S, Wirths O (2015) Neprilysin deficiency alters the neuropathological and behavioral phenotype in the 5XFAD mouse model of Alzheimer's disease. J Alzheimers Dis 44:1291-1302

17. International Parkinson's Disease Genomics C, Wellcome Trust Case Control C (2011) A Two-Stage Meta-Analysis Identifies Several New Loci for Parkinson's Disease. PLoS Genet 7:e1002142

18. Ishii J, Kitazawa R, Mori K, McHugh KP, Morii E, Kondo T, Kitazawa S (2008) Lipopolysaccharide suppresses RANK gene expression in macrophages by down-regulating PU.1 and MITF. J Cell Biochem 105:896-904

19. Jawhar S, Trawicka A, Jenneckens C, Bayer TA, Wirths O (2012) Motor deficits, neuron loss, and reduced anxiety coinciding with axonal degeneration and intraneuronal Abeta aggregation in the 5XFAD mouse model of Alzheimer's disease. Neurobiol Aging 33(196):e129-e196 e140

20. Kamphuis W, Kooijman L, Schetters S, Orre M, Hol EM (2016) Transcriptional profiling of CD11c-positive microglia accumulating around amyloid plaques in a mouse model for Alzheimer's disease. Biochim Biophys Acta (BBA) Mol Basis Dis 1862:1847-1860

21. Karch CM, Goate AM (2015) Alzheimer's disease risk genes and mechanisms of disease pathogenesis. Biol Psychiatry 77:43-51

22. Keren-Shaul H, Spinrad A, Weiner A, Matcovitch-Natan O, Dvir-Szternfeld R, Ulland TK, David E, Baruch K, Lara-Astaiso D, Toth B et al (2017) A Unique Microglia Type Associated with Restricting Development of Alzheimer's Disease. Cell 169:1276-1290 e1217

23. Kramer G, Wegdam W, Donker-Koopman W, Ottenhoff R, Gaspar P, Verhoek M, Nelson J, Gabriel T, Kallemeijn W, Boot RG et al (2016) Elevation of glycoprotein nonmetastatic melanoma protein B in type 1 Gaucher disease patients and mouse models. FEBS Open Bio 6:902-913

24. Krasemann S, Madore C, Cialic R, Baufeld C, Calcagno N, El Fatimy R, Beckers L, O'Loughlin E, Xu Y, Fanek Z et al (2017) The TREM2-APOE Pathway Drives the Transcriptional Phenotype of Dysfunctional Microglia in Neurodegenerative Diseases. Immunity 47:566-581 e569

25. Kuan C-T, Wakiya K, Dowell JM, Herndon JE, Reardon DA, Graner MW, Riggins GJ, Wikstrand CJ, Bigner DD (2006) Glycoprotein nonmetastatic melanoma protein $\mathrm{B}$, a potential molecular therapeutic target in patients with glioblastoma Multiforme. Clin Cancer Res 12:1970-1982

26. Lambert J-C, Heath S, Even G, Campion D, Sleegers K, Hiltunen M, Combarros O, Zelenika D, Bullido MJ, Tavernier B, et al: Genome-wide association study identifies variants at CLU and CR1 associated with Alzheimer\&\#39;s disease. Nat Genet 2009, 41:1094

27. Landel V, Baranger K, Virard I, Loriod B, Khrestchatisky M, Rivera S, Benech P, Feron $F$ (2014) Temporal gene profiling of the 5XFAD transgenic mouse model highlights the importance of microglial activation in Alzheimer's disease. Mol Neurodegener 9:33

28. Marques ARA, Gabriel TL, Aten J, van Roomen CPAA, Ottenhoff R, Claessen N, Alfonso P, Irún P, Giraldo P, Aerts JMFG, van Eijk M (2016) Gpnmb is a potential marker for the visceral pathology in Niemann-pick type $C$ disease. PLoS One 11:e0147208

29. Munter LM, Voigt P, Harmeier A, Kaden D, Gottschalk KE, Weise C, Pipkorn R, Schaefer M, Langosch D, Multhaup G (2007) GxxxG motifs within the amyloid precursor protein transmembrane sequence are critical for the etiology of $A \beta 42$. EMBO J 26:1702-1712

30. Nagahara Y, Shimazawa M, Ohuchi K, Ito J, Takahashi H, Tsuruma K, Kakita A, Hara H (2017) GPNMB ameliorates mutant TDP-43-induced motor neuron cell death. J Neurosci Res 95:1647-1665

31. Naj AC, Jun G, Beecham GW, Wang L-S, Vardarajan BN, Buros J, Gallins PJ, Buxbaum JD, Jarvik GP, Crane PK, et al: Common variants at MS4A4/ MS4A6E, CD2AP, CD33 and EPHA1 are associated with late-onset Alzheimer\&\#39;s disease. Nat Genet 2011, 43:436

32. Neal ML, Boyle AM, Budge KM, Safadi FF, Richardson JR (2018) The glycoprotein GPNMB attenuates astrocyte inflammatory responses through the CD44 receptor. J Neuroinflammation 15:73

33. Oakley H, Cole SL, Logan S, Maus E, Shao P, Craft J, Guillozet-Bongaarts A, Ohno M, Disterhoft J, Van Eldik L et al (2006) Intraneuronal beta-amyloid aggregates, neurodegeneration, and neuron loss in transgenic mice with five familial Alzheimer's disease mutations: potential factors in amyloid plaque formation. J Neurosci 26:10129-10140

34. Ogawa T, Nikawa T, Furochi H, Kosyoji M, Hirasaka K, Suzue N, Sairyo K, Nakano S, Yamaoka T, Itakura M et al (2005) Osteoactivin upregulates expression of MMP-3 and MMP-9 in fibroblasts infiltrated into denervated skeletal muscle in mice. Am J Phys Cell Phys 289:C697-C707

35. Orre M, Kamphuis W, Osborn LM, Jansen AHP, Kooijman L, Bossers K, Hol EM (2014) Isolation of glia from Alzheimer's mice reveals inflammation and dysfunction. Neurobiol Aging 35:2746-2760

36. Piccio L, Deming Y, Del-Águila JL, Ghezzi L, Holtzman DM, Fagan AM, Fenoglio C, Galimberti D, Borroni B, Cruchaga C (2016) Cerebrospinal fluid soluble TREM2 is higher in Alzheimer disease and associated with mutation status. Acta Neuropathol 131:925-933

37. Plotegher N, Duchen MR (2017) Mitochondrial dysfunction and neurodegeneration in lysosomal storage disorders. Trends Mol Med 23:116-134

38. Reinert J, Richard BC, Klafki HW, Friedrich B, Bayer TA, Wiltfang J, Kovacs GG, Ingelsson M, Lannfelt L, Paetau A et al (2016) Deposition of C-terminally truncated $A \beta$ species $A \beta 37$ and $A \beta 39$ in Alzheimer's disease and transgenic mouse models. Acta Neuropathologica Communications 4:1-12

39. Ripoll VM, Irvine KM, Ravasi T, Sweet MJ, Hume DA (2007) Gpnmb is induced in macrophages by IFN- $\gamma$ and lipopolysaccharide and acts as a feedback regulator of Proinflammatory responses. J Immunol 178:6557-6566

40. Rose AAN, Annis MG, Dong Z, Pepin F, Hallett M, Park M, Siegel PM (2010) ADAM10 releases a soluble form of the GPNMB/Osteoactivin extracellular domain with Angiogenic properties. PLoS One 5:e12093

41. Saul A, Sprenger F, Bayer TA, Wirths O (2013) Accelerated tau pathology with synaptic and neuronal loss in a novel triple transgenic mouse model of Alzheimer's disease. Neurobiol Aging 34:2564-2573

42. Schieb H, Kratzin H, Jahn O, Mobius W, Rabe S, Staufenbiel M, Wiltfang J, Klafki HW (2011) Beta-amyloid peptide variants in brains and cerebrospinal fluid from amyloid precursor protein (APP) transgenic mice: comparison with human Alzheimer amyloid. J Biol Chem 286:33747-33758

43. Schmittgen TD, Livak KJ (2008) Analyzing real-time PCR data by the comparative C(T) method. Nat Protoc 3:1101-1108

44. Selkoe DJ, Hardy J (2016) The amyloid hypothesis of Alzheimer's disease at 25 years. EMBO Molecular Medicine 8:595-608

45. Stalder M, Phinney A, Probst A, Sommer B, Staufenbiel M, Jucker M (1999) Association of microglia with amyloid plaques in brains of APP23 transgenic mice. Am J Pathol 154:1673-1684

46. Sturchler-Pierrat C, Abramowski D, Duke M, Wiederhold KH, Mistl C, Rothacher S, Ledermann B, Burki K, Frey P, Paganetti PA et al (1997) Two amyloid precursor protein transgenic mouse models with Alzheimer disease-like pathology. Proc Natl Acad Sci U S A 94:13287-13292

47. Suárez-Calvet $M$, Kleinberger $G$, Araque Caballero MÁ, Brendel M, Rominger A, Alcolea D, Fortea J, Lleó A, Blesa R, Gispert JD et al (2016) sTREM2 cerebrospinal fluid levels are a potential biomarker for microglia activity in early-stage Alzheimer's disease and associate with neuronal injury markers. EMBO Molecular Medicine 8:466-476

48. Tanaka H, Shimazawa M, Kimura M, Takata M, Tsuruma K, Yamada M, Takahashi H, Hozumi I (2012) Niwa J-i, Iguchi Y, et al: The potential of GPNMB as novel neuroprotective factor in amyotrophic lateral sclerosis. Sci Rep 2:573

49. Tseveleki V, Rubio R, Vamvakas S-S, White J, Taoufik E, Petit E, Quackenbush J, Probert $L$ (2010) Comparative gene expression analysis in mouse models for multiple sclerosis, Alzheimer's disease and stroke for identifying commonly regulated and disease-specific gene changes. Genomics 96:82-91

50. Walker DG, Lue L-F (2015) Immune phenotypes of microglia in human neurodegenerative disease: challenges to detecting microglial polarization in human brains. Alzheimers Res Ther 7:56

51. Weissmann R, Huttenrauch M, Kacprowski T, Bouter $Y$, Pradier L, Bayer TA, Kuss AW, Wirths O (2016) Gene expression profiling in the APP/PS1KI mouse model of familial Alzheimer's disease. J Alzheimers Dis 50:397-409

52. Weterman MAJ, Ajubi N, van Dinter IMR, Degen WGJ, van Muijen GNP, Ruiter DJ (1995) Bloemers HPJ: nmb, a novel gene, is expressed in low-metastatic human melanoma cell lines and xenografts. Int J Cancer 60:73-81

53. Williams MD, Esmaeli B, Soheili A, Simantov R, Gombos DS, Bedikian AY, Hwu P (2010) GPNMB expression in uveal melanoma: a potential for targeted therapy. Melanoma Res 20:184-190

54. Wirths O, Bayer TA (2012) Intraneuronal Abeta accumulation and neurodegeneration: lessons from transgenic models. Life Sci 91:1148-1152

55. Wirths O, Breyhan H, Schafer S, Roth C, Bayer TA (2008) Deficits in working memory and motor performance in the APP/PS1 ki mouse model for Alzheimer's disease. Neurobiol Aging 29:891-901

56. Wu H-C, Chen C-M, Chen Y-C, Fung H-C, Chang K-H, Wu Y-R (2018) DLG2, but not TMEM229B, GPNMB, and ITGA8 polymorphism, is associated with 
Parkinson's disease in a Taiwanese population. Neurobiology of Aging 64(158):e151-e158 e156

57. Xu Y, Chen Y, Ou R, Wei Q-Q, Cao B, Chen K, Shang H-F (2016) No association of GPNMB rs156429 polymorphism with Parkinson's disease, amyotrophic lateral sclerosis and multiple system atrophy in Chinese population. Neurosci Lett 622:113-117

58. Yin Z, Raj D, Saiepour N, Van Dam D, Brouwer N, Holtman IR, Eggen BJL, Möller T, Tamm JA, Abdourahman A et al (2017) Immune hyperreactivity of A $\beta$ plaque-associated microglia in Alzheimer's disease. Neurobiol Aging 55: $115-122$

59. Yu B, Alboslemy T, Safadi F, Kim M-H (2018) Glycoprotein nonmelanoma clone $B$ regulates the crosstalk between macrophages and mesenchymal stem cells toward wound repair. J Investig Dermatol 138:219-227

60. Zhang Y, Chen K, Sloan SA, Bennett ML, Scholze AR, O'Keeffe S, Phatnani HP, Guarnieri P, Caneda C, Ruderisch N et al (2014) An RNA-sequencing transcriptome and splicing database of glia, neurons, and vascular cells of the cerebral cortex. J Neurosci 34:11929-11947

61. Zhou L, Zhuo H, Ouyang H, Liu Y, Yuan F, Sun L, Liu F, Liu H (2017) Glycoprotein non-metastatic melanoma protein b (Gpnmb) is highly expressed in macrophages of acute injured kidney and promotes M2 macrophages polarization. Cell Immunol 316:53-60

62. Zigdon H, Savidor A, Levin Y, Meshcheriakova A, Schiffmann R, Futerman AH (2015) Identification of a biomarker in cerebrospinal fluid for Neuronopathic forms of Gaucher disease. PLoS One 10:e0120194

Ready to submit your research? Choose BMC and benefit from:

- fast, convenient online submission

- thorough peer review by experienced researchers in your field

- rapid publication on acceptance

- support for research data, including large and complex data types

- gold Open Access which fosters wider collaboration and increased citations

- maximum visibility for your research: over $100 \mathrm{M}$ website views per year

At BMC, research is always in progress.

Learn more biomedcentral.com/submissions 